\title{
Treatment of Rhinophyma by Surgical Excision and \\ Electrocautery: A Case Report and Review of Literature
}

\author{
Saadallah M. Al-Zacko ${ }^{1}$, Ayman S. Mohammad ${ }^{2}$ and Ameer S. Al-Zacko ${ }^{3}$ \\ 1. Consultant Plastic Surgeon, Al-Yanabee Medical Center, Mosul 41001, Iraq \\ 2. Dept. Plastic Surgery, Ninevah College of Medicine/University of Mosul, Mosul 41001, Iraq \\ 3. Dept. Plastic Surgery, Al-Jumhoori Teaching Hospital, Mosul 41001, Iraq
}

\begin{abstract}
Rhinophyma is a rare disease that primarily affects Caucasian men in the fifth to seventh decades of life. It is characterized by a progressive thickening of nasal skin, involving the lower two-thirds of the nose which may progress to large bulbous growths with dilated pores, causing lot of cosmetic and psychological concern and serving as a medium for occult cancers. Furthermore, impairment of breathing may coexist, making the surgical treatment necessary. Many treatment options are available for rhinophyma, but there is no standard treatment protocol. We report our experience in two bother patients with rhinophyma who underwent a combination of surgical excision with bipolar electrocautery and local infiltration of dilute epinephrine. It permits a spontaneous re-epithelialization in two weeks. Histological examination of the biopsy specimens revealed a hyperkeratosis of the epidermis and sebaceous gland hyperplasia. Both patients had excellent cosmetic and functional results. The described technique is simple, safe, efficient, and cost-effective approach to the treatment of rhinophyma.
\end{abstract}

Key words: Rhinophyma, surgical treatment, case report, tangential excision, electrocautery.

\section{Introduction}

Rhinophyma is a rare, disfiguring disease characterized by a progressive hypertrophy of the lower two-third the nose soft tissues. It leads to hyperemia and telangiectasia, causing dilated pilosebaceous pores with a reddish and bulky appearance, and affecting most frequently elderly Caucasian males [1]. It affects patients' quality of life and sometimes large rhinophymas can cause nasal airway obstruction and difficulty in eating [2]. It is believed to be the end stage of severe acne rosacea, but the exact etiology remains unknown [1]. In the past the rhinophyma was considered a clinical sign of alcoholism, but this relationship was never demonstrated [3]. Rhinophyma can be complicated by unnoticed skin malignancies. Occult basal cell carcinoma is estimated to occur in $3 \%$ to $10 \%$ of

Corresponding author: Professoor Saadallah M. Al-Zacko, FRCS(Ed.), research fields: plastic surgery (all field especially rhinoplasty \& cleft lip / palate) \& burns. rhinophyma cases [4-6].

In 1845, Ferdinand von Hebra used a terminology derived from the Greek rhino (nose) and phyma (growth), which resulted in rhinophyma becoming the universally accepted name [7]. It was described as early as the 15th century, as illustrated by a nobleman bulbous nose of the portrait of the "Old man and his Grandson" painted by Ghirlandaio in 1490, which strongly resembles what is today known as a rhinophyma [8].

The diagnosis is mostly clinical and should be differentiated from acne vulgaris, seborrheic dermatitis, lupus erythematosus, mycosis fungoides, sarcoidosis, and cutaneous tuberculosis [9]. It is histologically characterized by sebaceous gland hyperplasia, telangiectasias, hypervascularity and fibrovascular proliferation of the nasal dermis $[10,11]$.

Several treatment options are available such as surgery, dermabrasion, and laser therapy. The gold standard treatment for rhinophyma is surgical intervention, while the techniques of excision vary. 
Surgery for rhinophyma resection was done, back in the 19th century, when Von Langenbeck performed a complete resection of the skin, leaving it to heal by secondary intention [12].

Surgical treatment includes total eradication (full thickness excision) or subtotal eradication (partial thickness excision) of the diseased tissue. Total eradication, down to the loose areolar layer overlying the osteocartilaginous structure, and then, covering with skin grafts or flaps, needed for deeply infiltrating rhinophyma and those with underlying neoplasia. Subtotal eradication by tangential excision of diseased tissue, preserves the underlying sebaceous gland and allows a spontaneous reepithelization, that is not only a less complicated surgical procedure, but also guarantees a complete healing in two to three weeks, with better aesthetic results $[2,13,14]$.

We report our experience in two brother patients with rhinophyma treated successfully by surgical excision and bipolar electrocautery with excellent cosmetic and functional results and followed for at least six months. To our knowledge these are the first two cases of rhinophymas in two brothers treated with conservative excision followed by secondary healing.

\section{Case Report}

\subsection{Case 1}

A 70-year-old man, bus driver, presented to the plastic surgery private clinic in Mosul, complaining of 8 years history of a slowly progressive thickening of the nose skin with a foul odor, mainly affecting the tip of the nose (Fig. 1). This thickening gradually increased in size leading to distortion of the contour of the nose. The patient did not give history suggestive of photosensitivity redness or inflammatory lesions on the face. Its size at presentation caused cosmetic embarrassment. A significant history of sun exposure was described in his medical records, along with notes that he neither consumed alcohol nor a smoker.

Physical examination revealed firm bulbous enlargement of the tip and under surface of nose with peau d'orange appearance, telangiectasias, dilated pilosebaceous pores, and extruding sebum on pressure. There was not any palpable lymphadenopathy.

\subsection{Case 2}

A 66-year-old man, farmer, who is a younger brother of case one, presented with a bulbous enlargement of the tip of the nose with cosmetic disfigurement since 7 years. He observed a rapid increase in the size of the nose in the last two years (Fig. 2). In addition, he complains from partial nasal airway obstruction. No history of photosensitivity or inflammatory dermatological lesions was reported. His medical history revealed no alcoholism, but he is a smoker for 45 years. Its size at presentation caused psychological embarrassment.

Physical examination revealed a significant increase in nasal volume, mainly at the tip, with telangiectasias, cutaneous thickening, and keratinous material could easily be expressed. There was not any palpable lymphadenopathy.

Both patients underwent surgical excision of rhinophyma under general anesthesia with orotracheal intubation, and the area was infiltrated locally with 10 $\mathrm{mL}$ lidocaine $1 \%$ and epinephrine 1:100,000 solution to reduce postoperative pain and bleeding during the surgical treatment.

After adequate time for vasoconstriction, a tangential resection was performed layer by layer with a number 24 scalpel blade, removing linear segments of varying thickness (1-2 $\mathrm{mm}$ ) from the affected region, with preservation of the cartilages, perichondrium and periosteum to avoid the possibility of scarring. Hemostasis was achieved using bipolar electrocautery to reduce bleeding from the denuded area. At the end of the procedure the wound was covered with $10 \%$ povidone iodine pack, with the patient being discharged about two hours later. Then the wound was treated daily with local doxycycline ointment.

The nasal dorsum was re-epithelialized in both cases spontaneously from the retained glandular 
elements. Follow-up was continued with weekly visits until healing was completed by the third week. The surgical wound healed successfully with secondary intention and a restored normal nasal architecture. Erythema persisted for one month and had completely faded by two months (Figs. 3 and 4).

The excised tissue was sent for histopathological study, which revealed hyperkeratosis of the epidermis, marked lymphocytic inflammatory reaction, increased fibrous tissue with teleangiectatic vessels and sebaceous gland hyperplasia confirming the diagnosis of rhinophyma. Neoplastic cells were not seen.

These two patients showed good results with minimal scarring and improved breathing and satisfaction with the recovery of social and family relationship. Postoperative follow-up was continued up to six months which showed no signs of recurrence of rhinophyma.

\section{Discussion}

Rhinophyma is a rare slow-growing and disfiguring enlargement of the nose leading to a large, bulbous, and erythematous appearing nose with wide pores and thick skin. With progression, the aesthetic subunits of the nose become obliterated with the characteristic red to purplish telangiectasias and irregular, lobulated thickening of the skin of the nose. It is painless and extruding whitish sebum with the fetid smell on pressure. It can result in localized or generalized deformity of the nose, which often has a major cosmetic and psychological impact.

Rhinophyma occurs almost exclusively in middle aged to elderly men with a male/female ratio of 5:1 to 30:1 [15]. Patients often suffer from secondary nasal airway obstruction at the external nasal valves, as in our second case $[3,12,16]$. Other fairly rare sites have also been described, involving the chin (mentophyma), the forehead (frontophyma), and the ear (otophyma) [17].

It is believed to be the end stage of severe acne rosacea, but the exact etiology remains unknown [1].
A multifactorial origin with a primary etiology of unregulated superficial vasodilatation has been blamed. The extravasation leads to chronic edema of the dermal interstitium leading to local inflammation, fibrosis, and dermal and sebaceous gland hyperplasia $[3,12,16]$. There is evidence of associated genetic factors as cases of twins, uncles, or grandparents of patients affected have been described [18]. This goes with our two brother patients with rhinophyma.

Some risk factors for its development are described in the literature: exposure to sunlight, age (men over 40 years of age), and stress [10]. In mice, it has been shown that UVB light induces dermal angiogenesis and also increases vascular endothelial growth factor (VEGF) expression in keratinocytes [19]. Both our patients have history of excess exposure to sunlight for many years which may be an etiological factor of rhinophyma.

Malignancy may occur on phymatous skin, and rapid growth or ulceration should be considered as suspicious of malignant degeneration, thereby possibly resulting in basal cell carcinoma and, more rarely, squamous cell carcinoma or angiosarcoma [9]. In the reported cases, no associated neoplasia was found.

Surgical treatments are aimed at removing the excess tissue and restoring the natural appearance of the nose. The first surgical process for rhinophyma was applied by Daniel Sennert in 1629 [20]. In 1864 Stromeyer performed partial thickness excision of involved skin, allowing reepithelialization from retained sebaceous glands [21].

Many different surgical procedures have been described, depending on the size of the lesion and experience of the surgeon, including total excision of the involved tissues, with either flap closure or grafting of the defect; partial excision with healing by secondary intention; $\mathrm{CO}_{2}$ laser ablation; electrosurgery; and dermabrasion [22]. A simple surgical excision using a scalpel to shave off the abnormal tissue with electrocauterization of the bleeding points can be 
A Case Report and Review of Literature

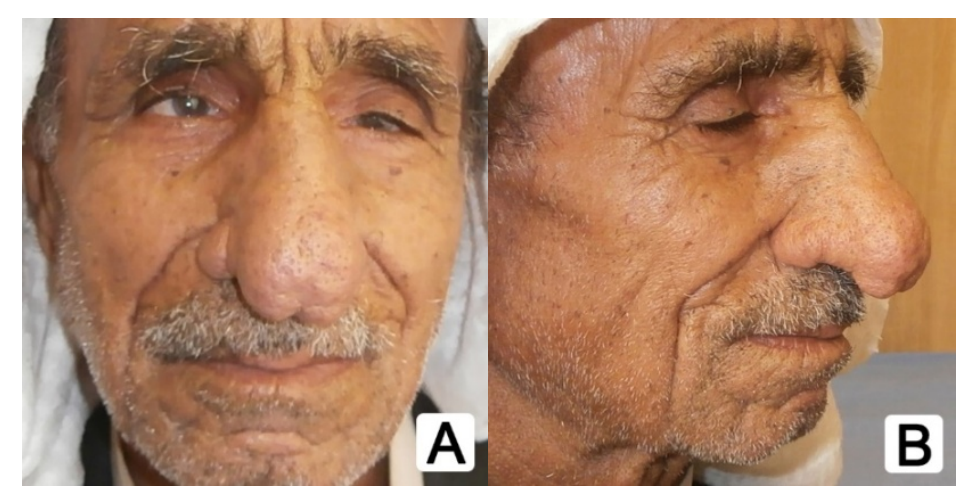

Fig. 1 Patient No. 1: (a and b) preoperative view.

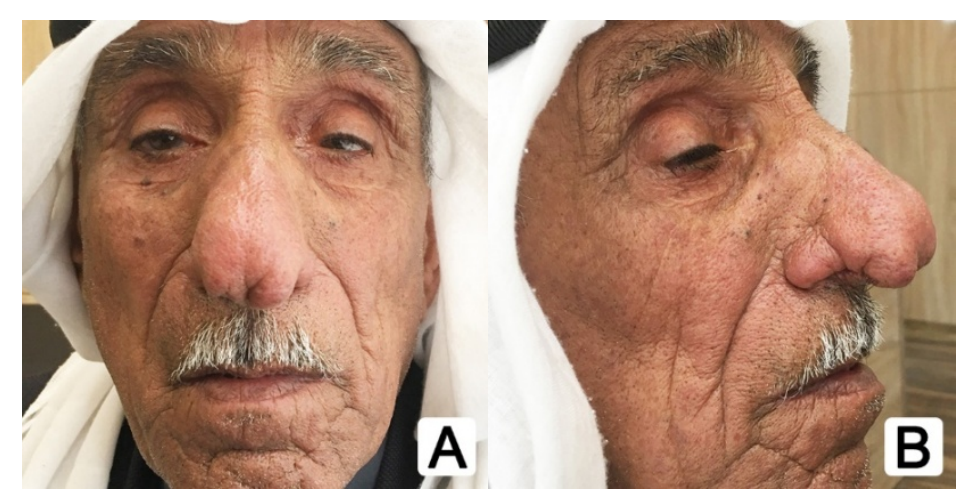

Fig. 2 Patient No. 2: (a and b) preoperative view.

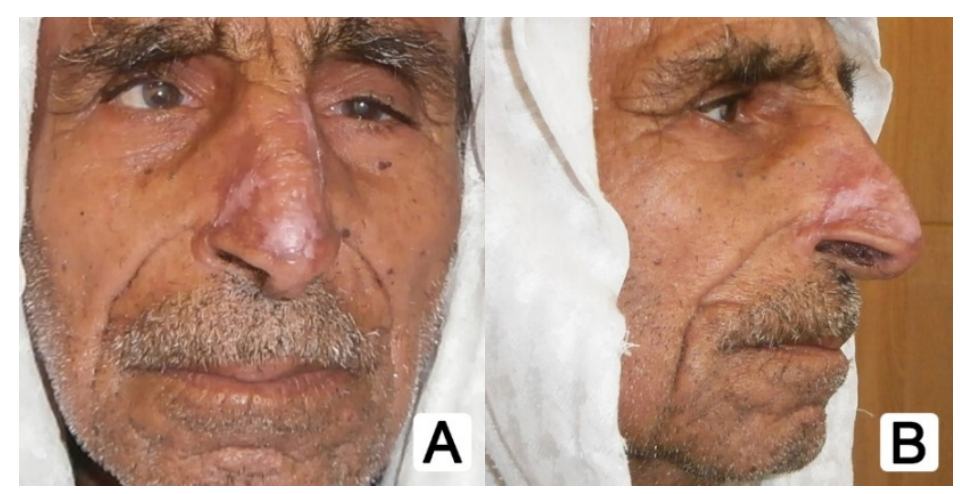

Fig. 3 Patient No. 1: (a and b) postoperative view after two months.

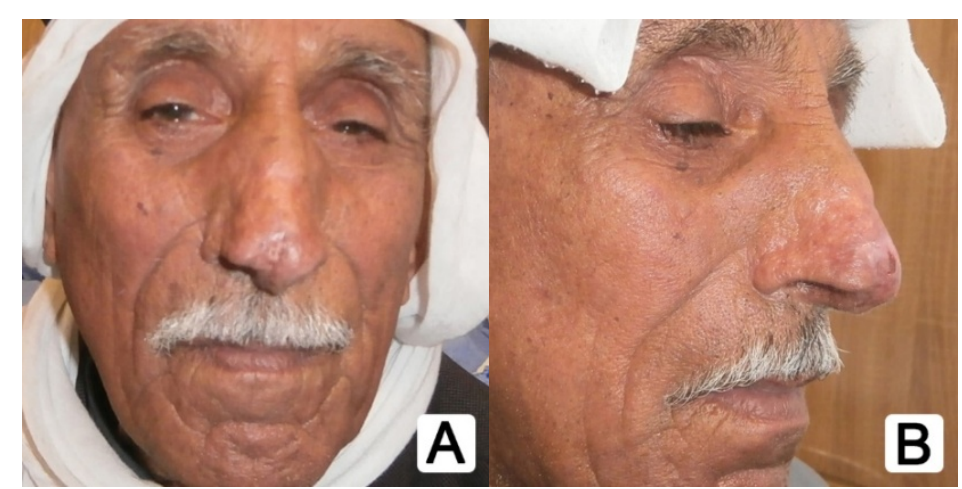

Fig. 4 Patient No. 2: (a and b) postoperative view after six months. 
considered as a good treatment option for rhinophyma. In our cases, rhinophymatous tissues are shaved off in layers with care taken not to injure the underline osteocartilagineous structures. We found that using a scalpel, with local infiltration of dilute epinephrine and bipolar electrocautery to control the bleeding allows a sharp and accurate removal of the diseased tissue and creating a smooth finish, which leads to good aesthetic results.

In our opinion, the operator needs to place his finger in the nostrils leaving a thickness of 2-3 mm above the cartilages and nasal bones. This allows accurate removal of the diseased tissue to the desired depth where the remaining fundi of hypertrophic sebaceous glands should be sufficient to re-epithelize the nose. This tangential excision and spontaneous re-epithelialization technique has been recommended by many authors [4, 13, 14, 23-26]. It is commonly reported that re-epithelialization of the wound after electrocoagulation takes between 10 and 15 days [27]. In our patients re-epithelialization was noticed in 15 days and healing was complete in three weeks. The authors advocate this procedure because of its efficiency, simplicity, safety, good hemostasis and guarantees good esthetic results. Unlike some other procedures, by excising the tissue, we were able to preserve a histopathologic specimen that can be examined for occult cancers. This also helps to exclude disorders that mimic rhinophyma, such as squamous cell carcinoma and angiomatous tumors.

Among the potential complications of electrocoagulation, which were not observed in the present study, are the formation of unsightly scarring, asymmetry and perforation of the nasal cartilage [28]. Mild dyschromia due to exposure to sunlight was reported in case 2. We advise shielding from the sun indefinitely and use of combined ultraviolet $\mathrm{A}$ and ultraviolet B sunscreens.

Here we have presented what are, to our knowledge, the first reported cases of rhinophyma in two brothers and the authors postulated that it may have a genetic factor. Our patients have healed well after electrosurgical treatment and are pleased with their improvement.

\section{Conclusion}

Rhinophyma is a rare, slow-growing and disfiguring enlargement of the nose leading to a bulbous lower third of the nose, causing lot of cosmetic and psychological concern and serving as a medium for occult cancers.

We report a simple, safe, efficient, and cost-effective approach to the treatment of rhinophyma using a scalpel and bipolar electrocautery with local infiltration of dilute epinephrine. It can be considered as a good treatment option with a short recovery time and excellent cosmetic and functional results. Furthermore, these are, to our knowledge, the first reported cases of rhinophyma in two brothers and the authors postulated that it may have a genetic factor.

\section{References}

[1] Wetzig, T., Averbeck, M., Simon, J. C., and Kendler, M. 2013. "New Rhinophyma Severity Index and Mid-Term Results Following Shave Excision of Rhinophyma." Dermatology 227 (1): 31-6.

[2] Plenk, H. P. 1995. "Rhinophyma, Associated with Carcinoma, Treated Successfully with Radiation." Plast Reconstr Surg 95: 559-62.

[3] Sadick, H., Goepel, B., Bersch, C., Goessler, U., Hoermann, K., and Riedel, F. 2008. "Rhinophyma: Diagnosis and Treatment Options for a Disfiguring Tumor of the Nose." Ann Plas Surg 61 (1): 114-20.

[4] Lloyd, K. M. 1990. "Surgical Correction of Rhinophyma.” Arch Dermatol 126 (6): 721-3.

[5] Piccolo, V., Baroni, A., Russo, T., and Schwartz, R. A. 2016. "Ruocco's Immunocompromised Cutaneous District." Int J Dermatol 55 (2): 135-41.

[6] Lutz, M. E., and Otley, C. C. 2001. "Rhinophyma and Coexisting Occult Skin Cancers.” Dermatol Surg 27 (2): 201-2.

[7] Mathes, S., Weinberger, S., and Hentz, V. 2006. Plastic Surgery: Tumors of Head, Neck and Skin. 2nd ed. Philadelphia: W. B. Saunders, 254.

[8] Claros, P., Sarr, M. C., Nyada, F. B., and Claros, A. 2018. "Rhinophyma: Our Experience Based on a Series of 12 
Cases.” Eur Ann Otorhinolaryngol Head Neck Dis. 135 (1): 17-20.

[9] Sperli, A. E., Freitas, J. O. G., and Fischler, R. 2009. "Rhinophyma: Treatment with High-Frequency Equipment (Radio Frequency).” Bras J Plást Surg 24 (4): 504-8.

[10] Reyes, J. A. E., and Valencia, D. P. P. 2012. "Rhinophyma: A Literature Review." Acta de Otorrinolaringología \& Cirugía de Cabeza y Cuello 40 (3): 220-7.

[11] Mancera, C. J., Cervantes, H. D., Monroy, Z. J., and Izquierdo, O. C. 2007. "Rhinophyma: Surgical Treatment with Use of Radiofrequency." Cir Plast 17 (3): 176-80.

[12] Rohrich, R. J., Griffin, J. R., and Adams, W. P. J. 2002. "Rhinophyma: Review and Update." Plast Reconstr Surg 110 (3): 860-9.

[13] Stucker, F. J., Hoasjoe, D. K., and Aarstad, R. F. 1993. "Rhinophyma: A New Approach to Hemostasis." Ann Otol Rhinol Laryngol 102 (12): 925-9.

[14] Har-El, G., Shapshay, S. M., Bohigian, R. K., Krespi, Y. P., and Lucente, F. E. 1993. "The Treatment of Rhinophyma: 'Cold' vs. Laser Techniques." Arch Otolaryngol Head Neck Surg 119: 628-31.

[15] Wiemer, D. R. 1987. "Rhinophyma." Clin Plast Surg 14 (2): $357-65$.

[16] Jansen, T., and Plewig, G. 1998. "Clinical and Histological Variants of Rhinophyma, Including Nonsurgical Treatment Modalities." Facial Plast Surg. 14 (4): 241-53.

[17] De Macedo, A. C., Sakai, F. D., De Vasconcelos, R. C., and Duarte, A. A. 2012. "Gnatophyma: A Rare Form of Rosacea.” Ann Bras Dermatol 87 (6): 903-5.

[18] Lucchese, I. C., Barazzetti, D. O., Avila, D. F., et al. 2017.
"Rhinophyma: A Surgical Treatment Option." Braz J Plast Surg 32 (2): 287-90.

[19] Tüzün, Y., Wolf, R., Kutlubay, Z., Karakuş, O., and Engin, B. 2014. "Rosacea and Rhinophyma." Clin Dermatol 32 (1): 35-46.

[20] Little, S. C., Stucker, F. J., Compton, A., and Park, S. S. 2012. "Nuances in the Management of Rhinophyma." Facial Plast Surg 28 (2): 231-7.

[21] Fisher, W. J. 1970. "Rhinophyma: Its Surgical Treatment.” Plast. Reconstr. Surg 45 (5): 466-70.

[22] Costa, T. C., Firme, W. A. A., Brito, L. M. R., Vieira, M. B. G., and Leite, L. A. S. 2010. "Rhinophyma: Surgical Options Used in the Plastic Surgery Service of the Hospital Agamenon Magalhães-PE." Braz J Plást Surg 25 (4): 633-6.

[23] Ersek, R. A., and Denton, D. R. 1984. "Rhinophyma: Treatment with Electrocautery and Silver-Impregnated Porcine Xenograft.” Plast Reconsr Surg 74 (2): 269-73.

[24] Furukawa, M., Kanetou, K., and Hamada, T. 1994. "Rhinophyma in Japan." Int J Dermatol 33 (1): 35-7.

[25] Silva, D. N., Santos, B. R. M., Branquinho, L. I., Melo, M. M., and Rosseto, M. 2016. "Combined Treatment for Rhinophyma.” Surg Cosmet Dermatol 8 (2): 167-71.

[26] Lazzeri, D., Agostini, T., and Spinelli, G. 2013. "Optimizing Cosmesis with Conservative Surgical Excision in a Giant Rhinophyma." Aesthetic Plast Surg 37 (1): 125-7.

[27] Bogetti, P., Boltri, M., Spagnoli, G., and Dolcet, M. 2002. "Surgical Treatment of Rhinophyma: A Comparison of Techniques." Aesthetic Plast Surg 26 (1): 57-60.

[28] Rordam, O. M., and Guldbakke, K. 2011. "Rhinophyma: Big Problem, Simple Solution.” Acta Derm Venereol. 91 (2): 188-9. 